\title{
Optimized C-trap Timing of an Orbitrap 240 Mass Spectrometer for High Throughput Screening and Native MS by IR-MALDESI
}

Kevan T. Knizner ${ }^{1}$, Michael C. Bagley ${ }^{1}$, Kenneth P. Garrard ${ }^{1,2}$,Jan-Peter Hauschild ${ }^{3}$, Fan $\mathrm{Pu}^{4}$, Nathaniel L. Elsen ${ }^{4}$, Jon D. Williams ${ }^{4}$, and David C. Muddiman ${ }^{1,5}$

${ }^{1}$ FTMS Laboratory for Human Health Research, Department of Chemistry, North Carolina State University, Raleigh, NC 27695, USA, ${ }^{2}$ Precision Engineering Consortium,

North Carolina State University, Raleigh, NC 27695, USA, ${ }^{3}$ Thermo Fisher Scientific (Bremen) GmbH, 28199 Bremen, Germany, ${ }^{4}$ Drug Discovery Science and Technology, AbbVie Inc., North Chicago, Illinois 60064, USA, ${ }^{5}$ Molecular Education, Technology and Research Innovation Center (METRIC), North Carolina State University, Raleigh, NC 27695, USA

Submitted to: Journal of the American Society for Mass Spectrometry

Submitted: December 11, 2021

Supplemental Material: 5 Pages / 3 Supplemental Figures / 1 Supplemental Table

Keywords: High Throughput Screening; IR-MALDESI; Orbitrap Mass Spectrometer; Ctrap

\section{*Author for Correspondence}

David C. Muddiman, Ph.D.

FTMS Laboratory for Human Health Research

Department of Chemistry

North Carolina State University

Phone: 919-513-0084

Email: dcmuddim@ncsu.edu 


\section{Supplementary Figures}

\begin{tabular}{|c|c|c|}
\hline Molecule & Formula & $\begin{array}{l}\text { Theoretical } \\
{[\mathrm{M}+\mathrm{H}]^{+}(\mathrm{m} / \mathrm{z})}\end{array}$ \\
\hline Caffeine & $\mathrm{C}_{8} \mathrm{H}_{10} \mathrm{~N}_{4} \mathrm{O}_{2}$ & 195.0877 \\
\hline Hexamethoxyphosphazene & $\mathrm{C}_{6} \mathrm{H}_{18} \mathrm{~N}_{3} \mathrm{O}_{6} \mathrm{P}_{3}$ & 322.0481 \\
\hline MRFA & $\mathrm{C}_{23} \mathrm{H}_{37} \mathrm{O}_{5} \mathrm{~N}_{7} \mathrm{~S}$ & 524.2650 \\
\hline Hexakis(2,2-difluoroethoxy)phosphazene & $\mathrm{C}_{12} \mathrm{H}_{18} \mathrm{~F}_{18} \mathrm{~N}_{3} \mathrm{O}_{6} \mathrm{P}_{3}$ & 622.0289 \\
\hline \multirow[t]{6}{*}{ Hexakis(2,2,3,3-tetrafluoropropoxy)phosphazene } & $\mathrm{C}_{18} \mathrm{H}_{18} \mathrm{~F}_{24} \mathrm{~N}_{3} \mathrm{O}_{6} \mathrm{P}_{3}$ & 922.0098 \\
\hline & $\mathrm{C}_{20} \mathrm{H}_{18} \mathrm{~F}_{28} \mathrm{~N}_{3} \mathrm{O}_{6} \mathrm{P}_{3}$ & 1022.0034 \\
\hline & $\mathrm{C}_{22} \mathrm{H}_{18} \mathrm{~F}_{32} \mathrm{~N}_{3} \mathrm{O}_{6} \mathrm{P}_{3}$ & 1121.9970 \\
\hline & $\mathrm{C}_{24} \mathrm{H}_{18} \mathrm{~F}_{36} \mathrm{~N}_{3} \mathrm{O}_{6} \mathrm{P}_{3}$ & 1221.9906 \\
\hline & $\mathrm{C}_{26} \mathrm{H}_{18} \mathrm{~F}_{40} \mathrm{~N}_{3} \mathrm{O}_{6} \mathrm{P}_{3}$ & 1321.9843 \\
\hline & $\mathrm{C}_{28} \mathrm{H}_{18} \mathrm{~F}_{44} \mathrm{~N}_{3} \mathrm{O}_{6} \mathrm{P}_{3}$ & 1421.9779 \\
\hline \multirow[t]{6}{*}{ Ultramark 1621} & $\mathrm{C}_{30} \mathrm{H}_{18} \mathrm{~F}_{48} \mathrm{~N}_{3} \mathrm{O}_{6} \mathrm{P}_{3}$ & 1521.9715 \\
\hline & $\mathrm{C}_{32} \mathrm{H}_{18} \mathrm{~F}_{52} \mathrm{~N}_{3} \mathrm{O}_{6} \mathrm{P}_{3}$ & 1621.9651 \\
\hline & $\mathrm{C}_{34} \mathrm{H}_{18} \mathrm{~F}_{56} \mathrm{~N}_{3} \mathrm{O}_{6} \mathrm{P}_{3}$ & 1721.9587 \\
\hline & $\mathrm{C}_{36} \mathrm{H}_{18} \mathrm{~F}_{60} \mathrm{~N}_{3} \mathrm{O}_{6} \mathrm{P}_{3}$ & 1821.9523 \\
\hline & $\mathrm{C}_{38} \mathrm{H}_{18} \mathrm{~F}_{64} \mathrm{~N}_{3} \mathrm{O}_{6} \mathrm{P}_{3}$ & 1921.9459 \\
\hline & $\mathrm{C}_{40} \mathrm{H}_{18} \mathrm{~F}_{68} \mathrm{~N}_{3} \mathrm{O}_{6} \mathrm{P}_{3}$ & 2021.9395 \\
\hline Hexakis(1h,1h,7h-perfluoroheptoxy)phosphazene & $\mathrm{C}_{42} \mathrm{H}_{18} \mathrm{~F}_{72} \mathrm{~N}_{3} \mathrm{O}_{6} \mathrm{P}_{3}$ & 2121.9332 \\
\hline
\end{tabular}

Supplementary Table 1: Molecular species of Pierce ${ }^{\mathrm{TM}}$ Flexmix $^{\mathrm{TM}}$ calibration solution (Flexmix) within the studied $\mathrm{m} / \mathrm{z}$ range. The molecular formula and theoretical protonated adduct $\mathrm{m} / \mathrm{z}$ of each specie is listed. Ions of interest are shaded green. 
A

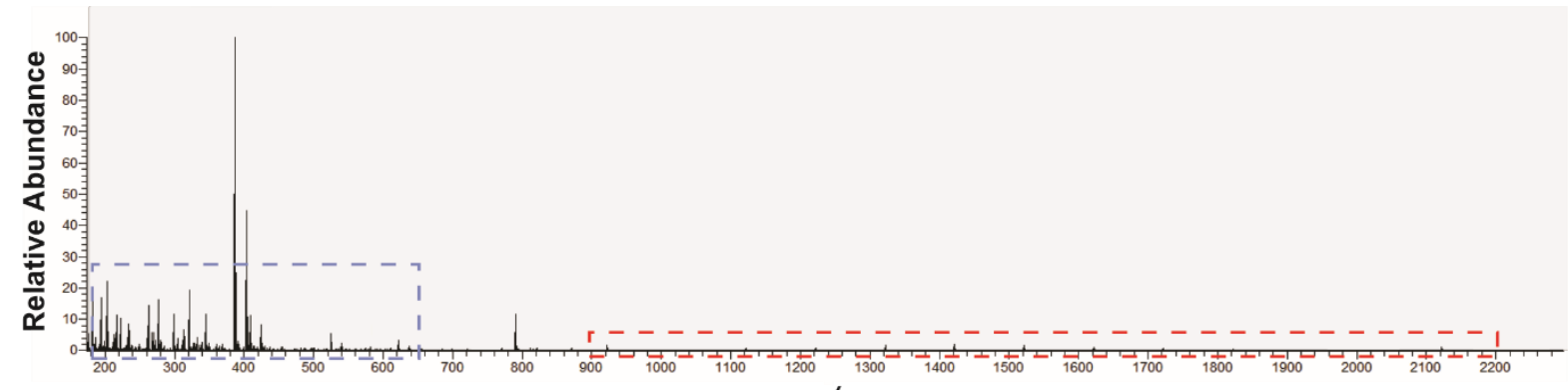
$m / z$

B

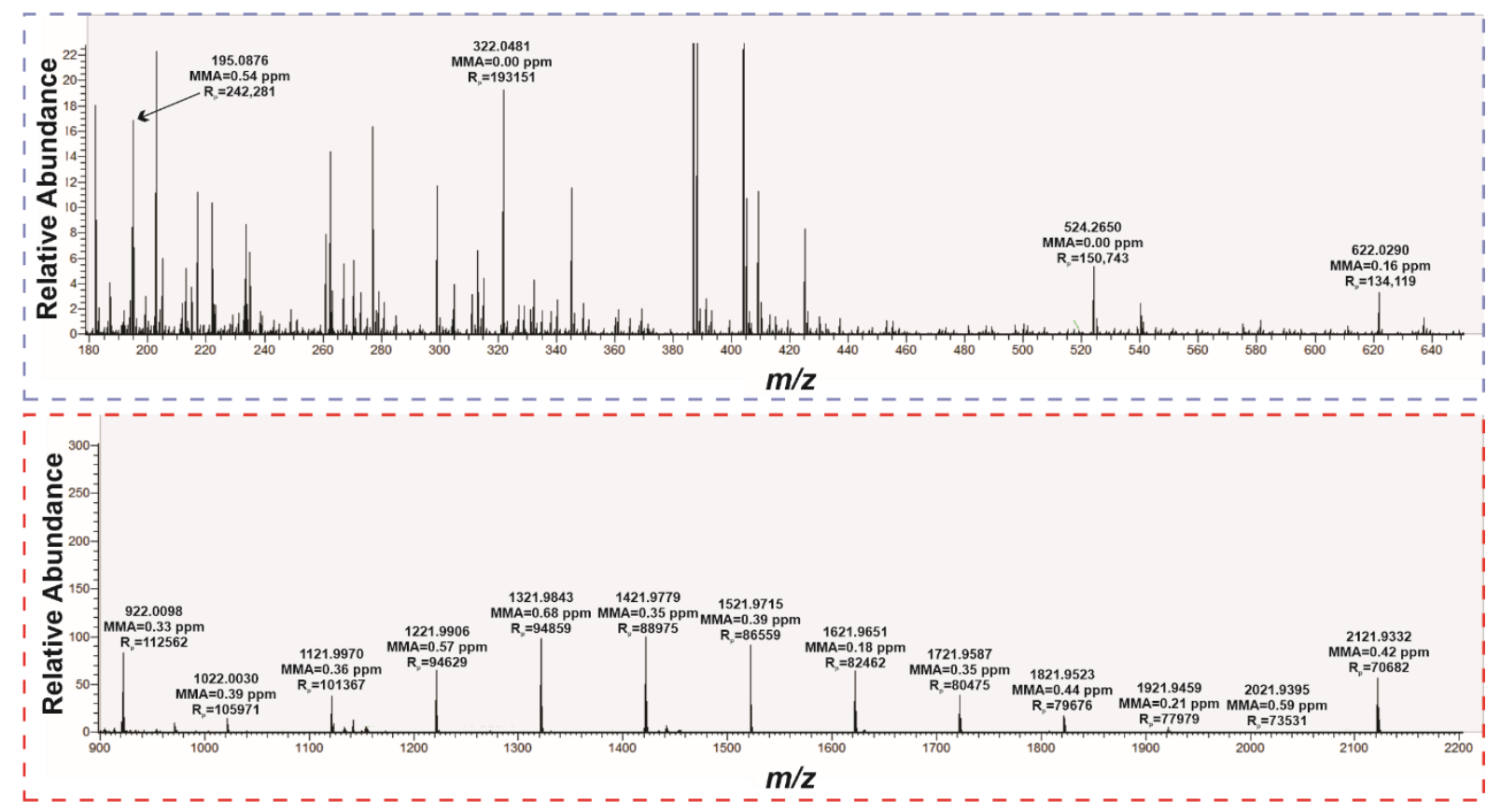

Supplementary Figure 1: A) The average mass spectrum of Flexmix by IR-MALDESI MS over $m / z$ range 175 2275. The zoomed in mass spectra with each Flexmix ion annotated with its respective mass measurement accuracy (MMA) and the measured resolution $\left(R_{p}\right)$ of its peak over $\left.\mathbf{B}\right) \mathrm{m} / z 190-650$ and $\mathbf{C}$ ) $\mathrm{m} / z 900-2200$. The mass spectrum was recorded using an Orbitrap Exploris ${ }^{\mathrm{TM}} 240$ mass spectrometer with the resolution set to 240,000 FWHM at $m / z 200$. The automatic gain control was disabled, the microscan count was fixed at 1 , and the ion accumulation time was fixed at $25 \mathrm{~ms}$ starting at the first laser pulse of each analysis. The $2970 \mathrm{~nm}$ laser fired a burst of 9 pulses at a pulse rate of $10 \mathrm{kHz}$ for each measurement. The electrospray composition was 50:50 (v/v) methanol/water with $0.2 \%$ formic acid and a flowrate fixed at $2 \mu \mathrm{L} / \mathrm{min}$. A $3.6 \mathrm{kV}$ potential was applied to the emitter tip. 
A

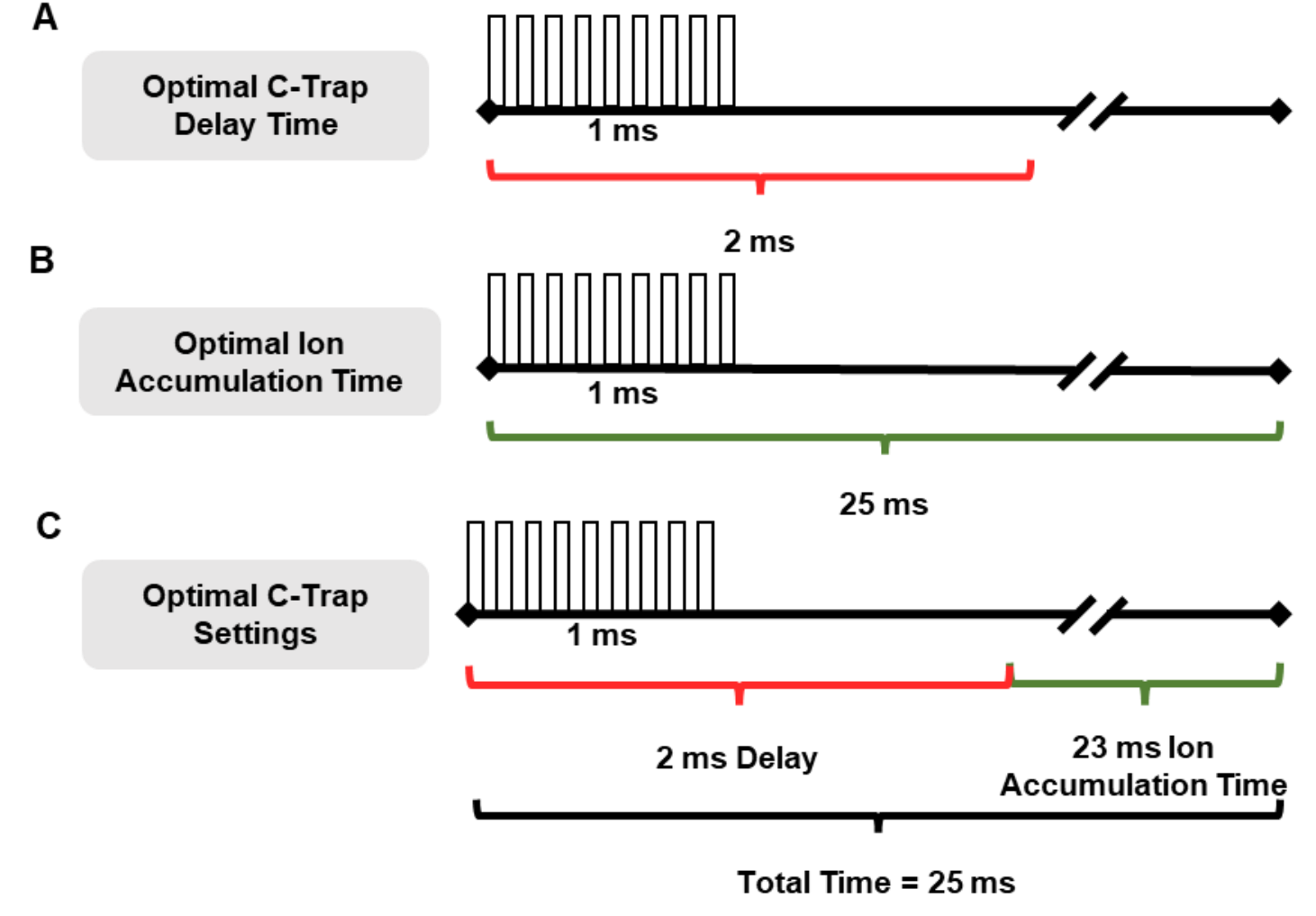

Supplementary Figure 2: Summary of the optimal settings for A) The optimal C-trap Accumulation time of $25 \mathrm{~ms}$ relative to the first laser pulse of the burst at $10 \mathrm{kHz}$, B) the optimal C-trap delay time of $2 \mathrm{~ms}$ relative to the first laser pulse, and $\mathbf{C}$ ) the resulting optimized $\mathbf{C}$-trap opening scheme consisting of a $2 \mathrm{~ms}$ delay of opening the C-trap with respect to the first laser pulse followed by keeping the C-trap open for 23 ms. 


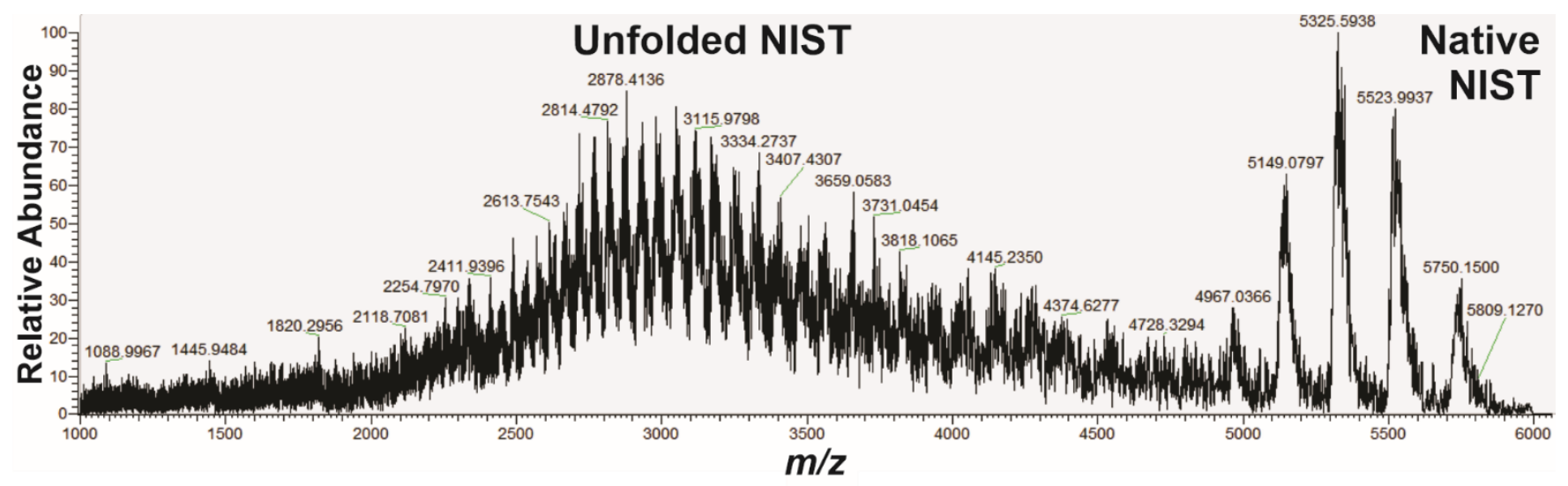

Supplementary Figure 3: A) Mass spectrum of $25 \mu \mathrm{M}$ NISTmAb (NIST) in $100 \%$ water over $\mathrm{m} / \mathrm{z}$ 1000-6000. The ion accumulation time was fixed at $150 \mathrm{~ms}$ and the resolution was set to $15,000_{\mathrm{FWHM}}$ at $\mathrm{m} / \mathrm{z} 200$. The S-lens RF level was $200 \%$. The laser fired 9 pulses at $10 \mathrm{kHz}$. The electrospray solution consisted of 50:50 (v/v) methanol $/$ water with $0.2 \%$ formic acid and the flowrate was fixed at $2 \mu \mathrm{L} / \mathrm{min}$. A potential of $3.6 \mathrm{kV}$ was applied to electrospray emitter tip. 